\title{
Improving the seasonal cycle and interannual variations of biomass burning aerosol sources
}

\author{
S. Generoso ${ }^{1}$, F.-M. Bréon ${ }^{1}$, Y. Balkanski ${ }^{1}$, O. Boucher ${ }^{2}$, and M. Schulz ${ }^{1}$ \\ ${ }^{1}$ Laboratoire des Sciences du Climat et de l'Environnement, CEA/CNRS, Gif-sur-Yvette, France \\ ${ }^{2}$ Laboratoire d'Optique Atmosphérique, CNRS / Université des Sciences et Technologies de Lille, Villeneuve d'Ascq, France
}

Received: 31 January 2003 - Published in Atmos. Chem. Phys. Discuss.: 15 April 2003

Revised: 9 July 2003 - Accepted: 29 July 2003 - Published: 22 August 2003

\begin{abstract}
This paper suggests a method for improving current inventories of aerosol emissions from biomass burning. The method is based on the hypothesis that, although the total estimates within large regions are correct, the exact spatial and temporal description can be improved. It makes use of open fire detection from the ATSR instrument that is available since 1996. The emissions inventories are re-distributed in space and time according to the occurrence of open fires. Although the method is based on the night-time hot-spot product of the ATSR, other satellite biomass burning proxies (AVHRR, TRMM, GLOBSCAR and GBA2000) show similar distributions.

The impact of the method on the emission inventories is assessed using an aerosol transport model, the results of which are compared to sunphotometer and satellite data. The seasonal cycle of aerosol load in the atmosphere is significantly improved in several regions, in particular South America and Australia. Besides, the use of ATSR fire detection may be used to account for interannual events, as is demonstrated on the large Indonesian fires of 1997, a consequence of the 1997-1998 El Niño. Despite these improvements, there are still some large discrepancies between the simulated and observed aerosol optical thicknesses resulting from biomass burning emissions.
\end{abstract}

\section{Introduction}

Aerosols affect the Earth radiative balance through diverse processes (direct and indirect effects), which are qualitatively well understood (Charlson et al., 1992;Twomey, 1977) but quantitatively still poorly known (Haywood and Boucher, 2000; IPCC, 2001). There are many evidence of a large effect of aerosols on climate both at regional (Léon et al., 2002) and

Correspondence to: S. Generoso

(generoso@1sce.saclay.cea.fr) global (Bréon et al., 2002) scale. Improving our knowledge requires, in particular, a better representation of aerosols in atmospheric models, which requires, among others, an accurate representation of sources (see Fig. 4 of Charlson et al., 1992). In this paper, we focus on biomass burning, which is the main source of carbonaceous aerosols (Black Carbon (BC) and Organic Carbon, OC). The two emission inventories most often used in general circulation models (GCM) are that of Liousse et al. (1996) and GEIA (Global Emissions Inventory Activity, a part of the International Global Atmospheric Chemistry (IGAC) Project). Although satellite data have been used to describe the monthly distribution of emissions over Africa (Cooke et al., 1996), the seasonal cycles are uncertain in many regions. In addition, interannual variations are not accounted for in these inventories. Satellites are well suited to provide seasonal and inter-annual information because of their global and continuous coverage. The present study describes a method that generates emission maps of biomass burning aerosol, which couples the inventories (Lavoué et al., 2000; Liousse et al., 1996) to the occurrence of fires as detected by ATSR-2 (Along Track Scanning Radiometer). Recently Schultz (2002) and Duncan et al. (2003) have presented methods that are based on a similar idea. Duncan et al. (2003) use the 20 years TOMS aerosol index to quantify the interannual variability over an extended time period. A major difference of our method is that the biomass burning location is redistributed in space within large regions, as will be discussed in Sect. 2. In addition, the present work shows atmospheric transport simulations of the aerosol loads using both the original and the corrected inventories, which allows a direct analysis of the method impact through a comparison to aerosol load sunphotometer measurement. Finally, we make use of multiyear optical thickness simulation and measurements, which permit an analysis of the seasonal and interannual variability. 


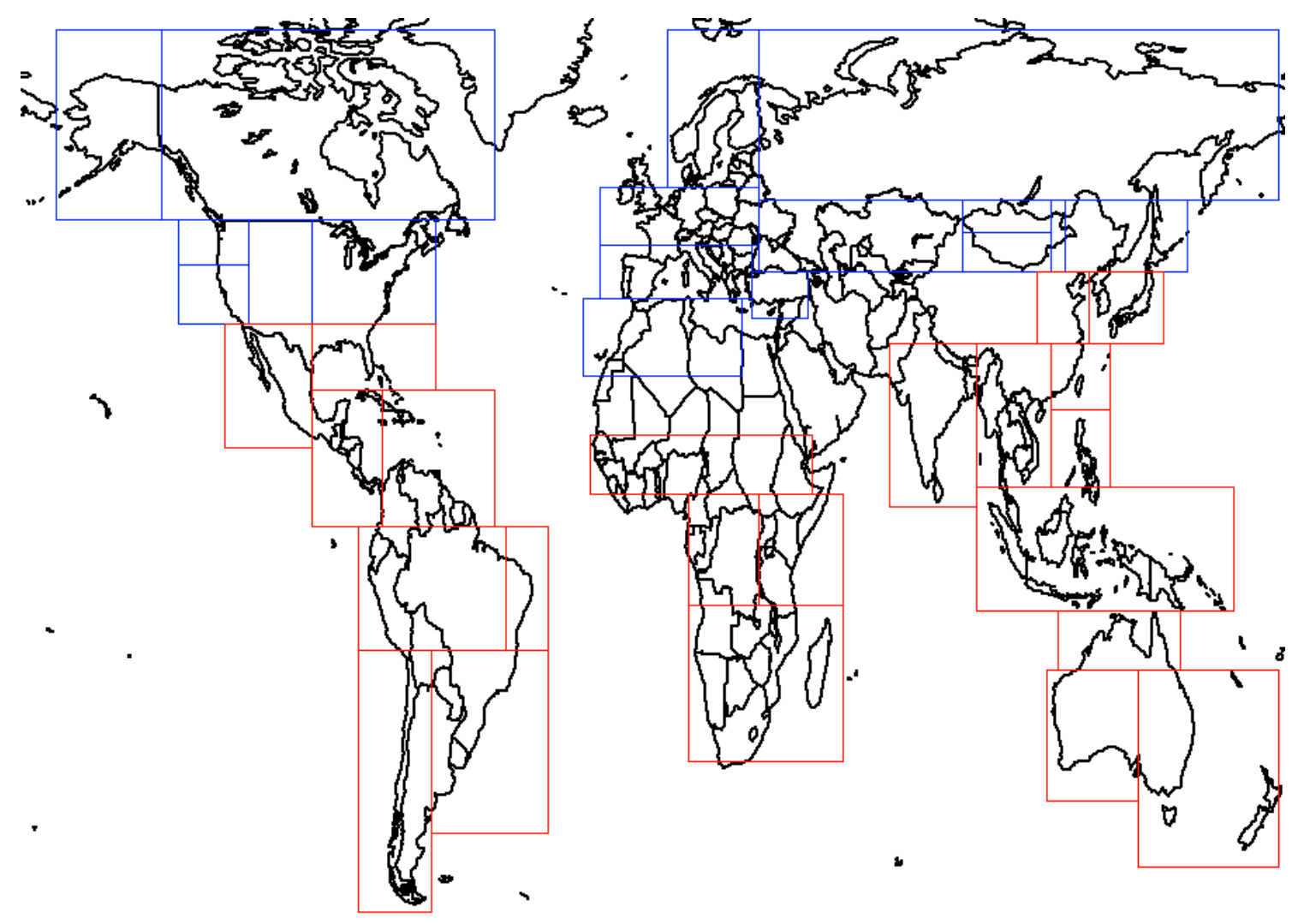

Fig. 1. Regional boxes used to build the emission maps. The boxes have been defined to distinguish areas with a fairly homogeneous vegetation cover and fire seasonal cycle.

\section{Method}

The monthly emission maps have been created as follow. First, the globe is divided into boxes that contain fairly homogeneous vegetation cover and fire season. The regions have been selected based upon MODIS land cover maps (http://modis-land.gsfc.nasa.gov/). In high latitude regions, the boxes follow the work of Lavoué et al. (2000), based on state borders and dominant vegetation (blue boxes in Fig. 1). Within each box, we compute the total annual emission according to the inventories.

Similarly, we compute within each box the total number of fires detected by the ATSR instrument during the period [January 1997-May 1997] U [June 1998-December 2001]. The period from June 1997 to May 1998 was omitted since it is strongly affected by an El Niño event, which resulted in very abnormal fire activity. We also removed from the datasets the "hot-spots" occurring in the same place during several months, as those are likely to be a result of industrial flares. The hot-spots, likely to be agricultural or wild fires, are detected based on a simple $317 \mathrm{~K}$ threshold on the $3.7 \mu \mathrm{m}$ channel on night-time observations (Arino and Melinotte, 1995). This product appears well suited for our needs as it is sensitive to fires that are small compared to the
$1 \times 1 \mathrm{~km}^{2}$ pixel, and because there is no orbit drift on the platform, which makes possible year-to-year comparisons. On the other hand, it suffers from well-known drawbacks that are discussed in the next section. Since a cloud presence will prevent the satellite detection of an underlying fire, a cloud coverage correction was applied by weighting the number of fires by $(1-\mathrm{C})^{-1}$ where $\mathrm{C}$ is the monthly climatological cloud cover (New et al., 1999).

From these two datasets, we compute for each box the ratio between the annual emitted quantities of carbonaceous aerosols $(\mathrm{Q})$ and the annual mean number of detected fires after having applied the cloud cover correction $(\mathrm{N})$. This Emission Constant (EC) is a statistical estimate of the emitted mass per detected fire. It varies depending on the box but is assumed constant within a given box, all through the year and from one year to the next.

Using EC and the monthly hot-spot distributions at the chosen resolution, we compute an emission estimate for all months when ATSR data is available (July 1996 to January 2002 at the time of the study). In the results presented in the following, the resolution was chosen in agreement with the atmospheric model resolution $(3.75 \times 2.5$ degrees in longitude and latitude, respectively) although the same procedure would apply to finer grids. In order to provide an emission 

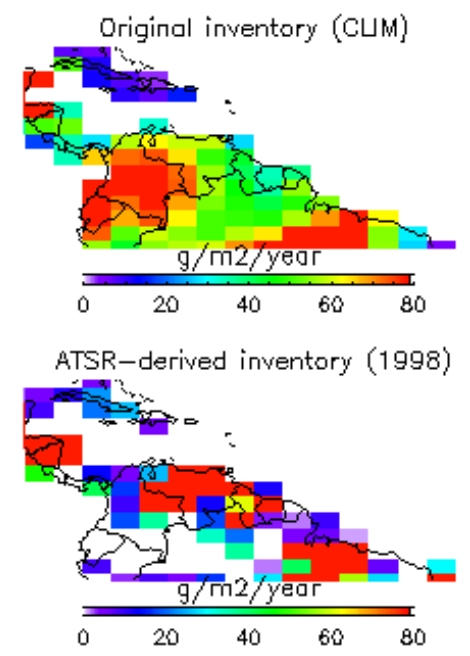

ATSR-derived inventory (2000)

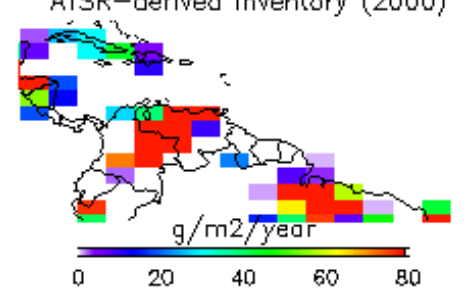

GBAZOOO + GLOBSCAR $\{2000)$

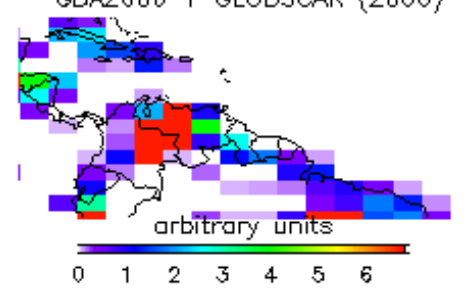

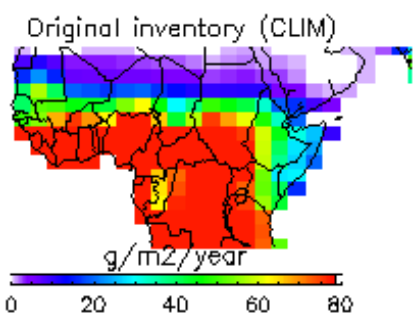

ATSR-derived inventory (1998)

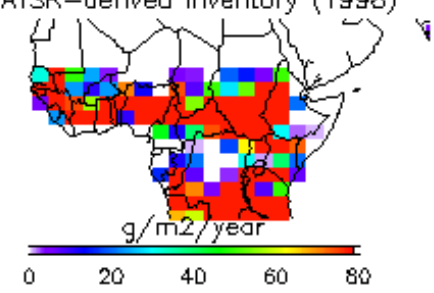

ATSR-derived inventory (2000)

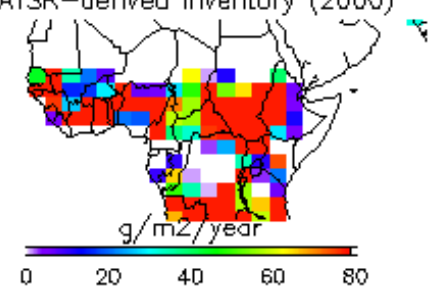

GBA2000 + GLDESCAR (2000)

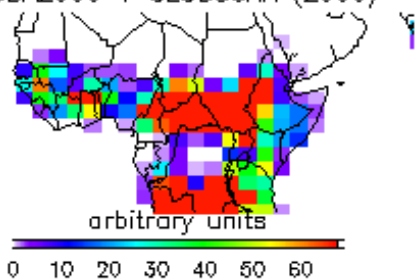

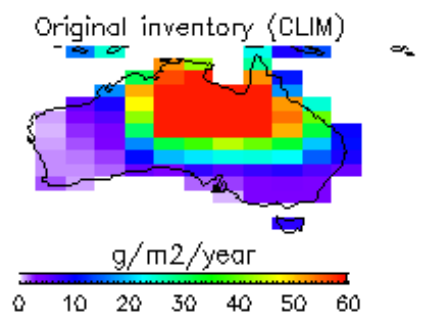

ATSR-derived inventory (1998)

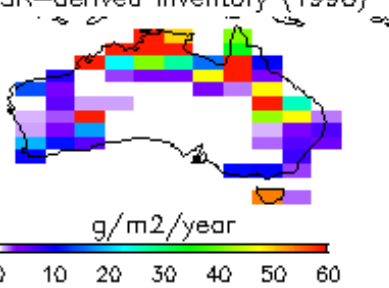

ATSR-derived inventory (2000)

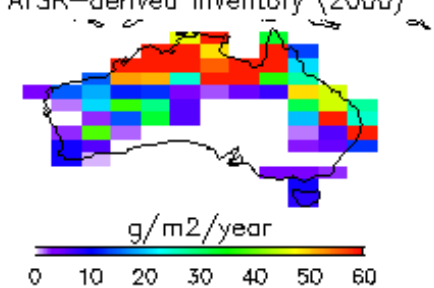

GBA2000 + GLOBSCAR (2000)

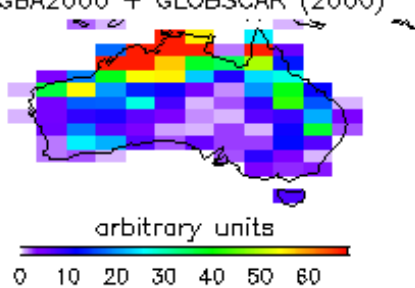

Fig. 2. Several proxies of biomass burning activity over Central and South America (left), Africa (center) and Australia (right). First line is the original inventory (from Liousse et al., 1996). The two middle lines are the corrected inventories for 1998 and 2000 respectively. The bottom line is a proxy based on the estimates of burnt surfaces by GBA and GLOBSCAR (averaged value of the two is used here).

estimate for the periods when no ATSR data is available, we also computed a "climatological" monthly emission based on the mean number of fires observed during a given month for the same period that excludes El Niño.

In Schultz (2002) and Duncan et al. (2003), the scaling factor is computed for each $1^{\circ}$ square grid box, whereas we estimate a value for each of the large regions shown in Fig. 1. In this way, the inventory emissions are redistributed over the season as in the above methods, but also within the boxes of Fig. 1. Figure 2 presents three examples of spatial redistribution. The first one concerns the Northern countries of South America (first row of Fig. 2). The original inventory shows a maximum of the annual estimates that extends from the Western part of Venezuela to Colombia and Ecuador. On the other hand, the ATSR-derived inventory shows for 1998 a maximum area that extends from Venezuela to Suriname, thus largely shifted to the North-East. We also show the ATSR corrected estimate for 2000 as a fully independent proxy of biomass burning is available for this year. The spatial distribution of burned surfaces (lower figure) is much closer to the ATSR corrected inventory than to the original version (top figure). This is a strong indication of the positive impact of spatial redistribution. When the scaling is applied on boxes that are small in comparison with typical size of biomass burning regions, as in Schultz (2002) the inventories are only corrected for any temporal deficiency. Duncan et al. (2003) proposed a method to account for spatial redistribution, which applies differently in function of the regions. For some regions the distribution of the base inventory is not modified. Other examples are shown in Fig. 2 concerning the Northern part of Africa and Australia. The three cases clearly indicate that the corrected inventory agree much better than the original with the estimates of burnt surfaces. 

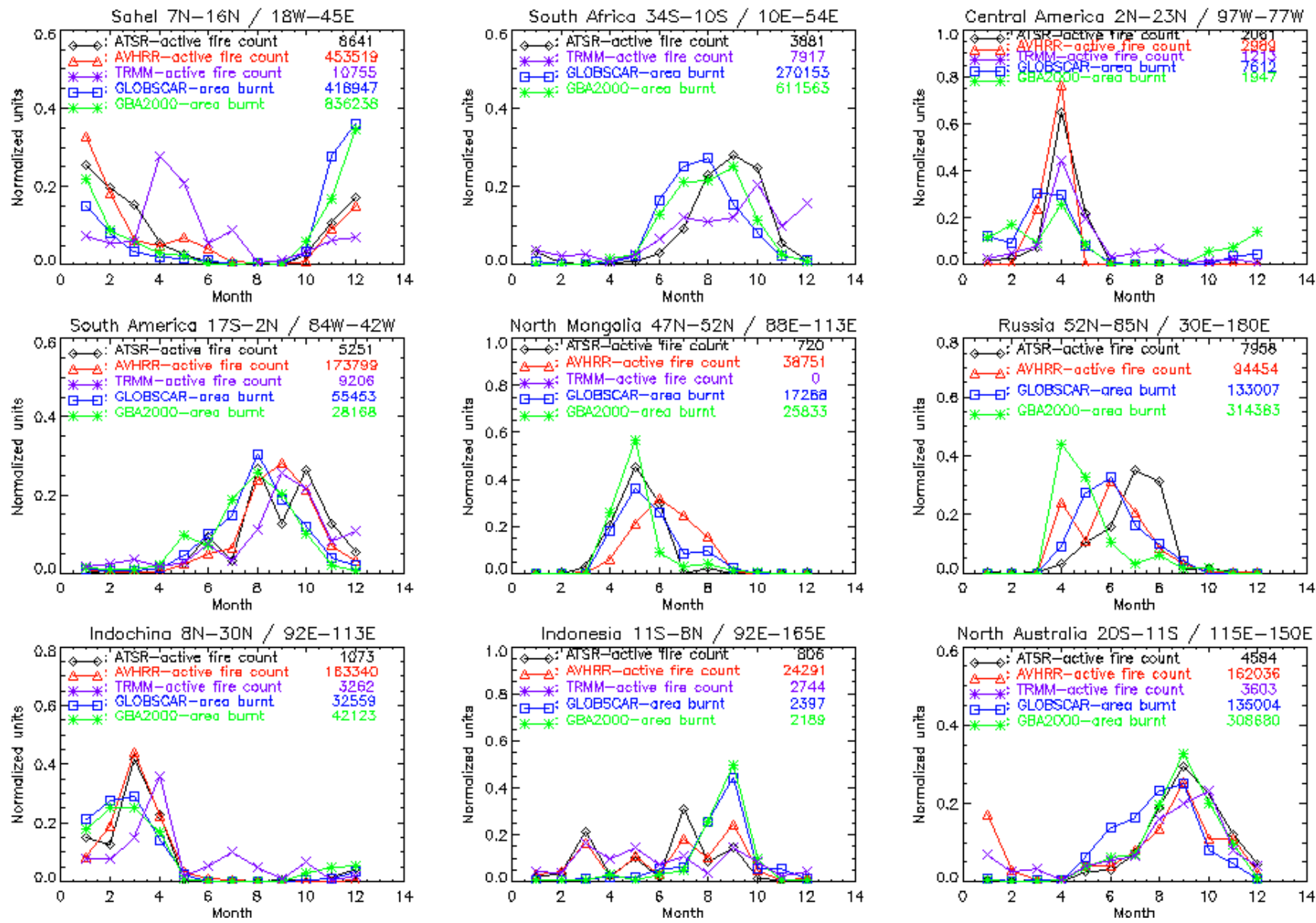

Fig. 3. Comparisons between five global fire products for nine selected regions. The number of fires for ATSR, TRMM and AVHRR and the burnt area for GLOBSCAR and GBA2000 (in arbitrary units) are plotted as a function of time and for the year 2000. Numbers shown close to the name of the datasets correspond to the total number of occurrences (fires for ATSR, TRMM, AVHRR; burnt area for GLOBSCAR and GBA2000) detected in the year in the given region.

\section{Discussion}

\subsection{Representativity of the night-time detection}

The method provides a simple way to introduce temporal and spatial variations of biomass burning in the inventories. On the other hand, it requires unproven assumptions. A first assumption stems from the use of night observations only. As a consequence, the emission distribution is only based on fires that extend into the night. This hypothesis does not impact the mean emissions in a box as it is implicitly accounted for in the Emission Constant EC. On the other hand, the method will fail if the ratio between the number of daytime and night-time fires varies significantly, within a box, between months or between the various pixels of the emission grid. To assess the representativity of the night-time fires used in this study, we have compared the global fire count products from the AVHRR (daily) (World Fire Web from the Joint Research Center of the European Commission available at http://www.gvm.jrc.it/tem/wfw/wfw.htm), ATSR (night-time), TRMM (daily) (Giglio et al., 2003, 2000), and the GBA2000 (Grégoire et al., 2003) and GLOBSCAR (Simon et al., 2003) burnt area products. We have plotted the number of fires for ATSR, TRMM and AVHRR and the burnt area for GLOBSCAR and GBA2000 (in arbitrary units) as a function of time and for the year 2000. The comparisons are made within the large regions of Fig. 1.

Figure 3 shows the results for nine selected regions. The same plots were made for all the regions of Fig. 1. We only show a representative sample. There are two main types of proxies. ATSR, AVHRR and TRMM products are based on the detection of active fires (hot- spots). On the other hand, GLOBSCAR and GBA2000 detect the presence of burnt surfaces. In general, there is a good agreement between the different proxies, in particular over the major zones of biomass burning: Sahel (except TRMM), South and Central America, Mongolia, Indochina Peninsula, and Australia (except 


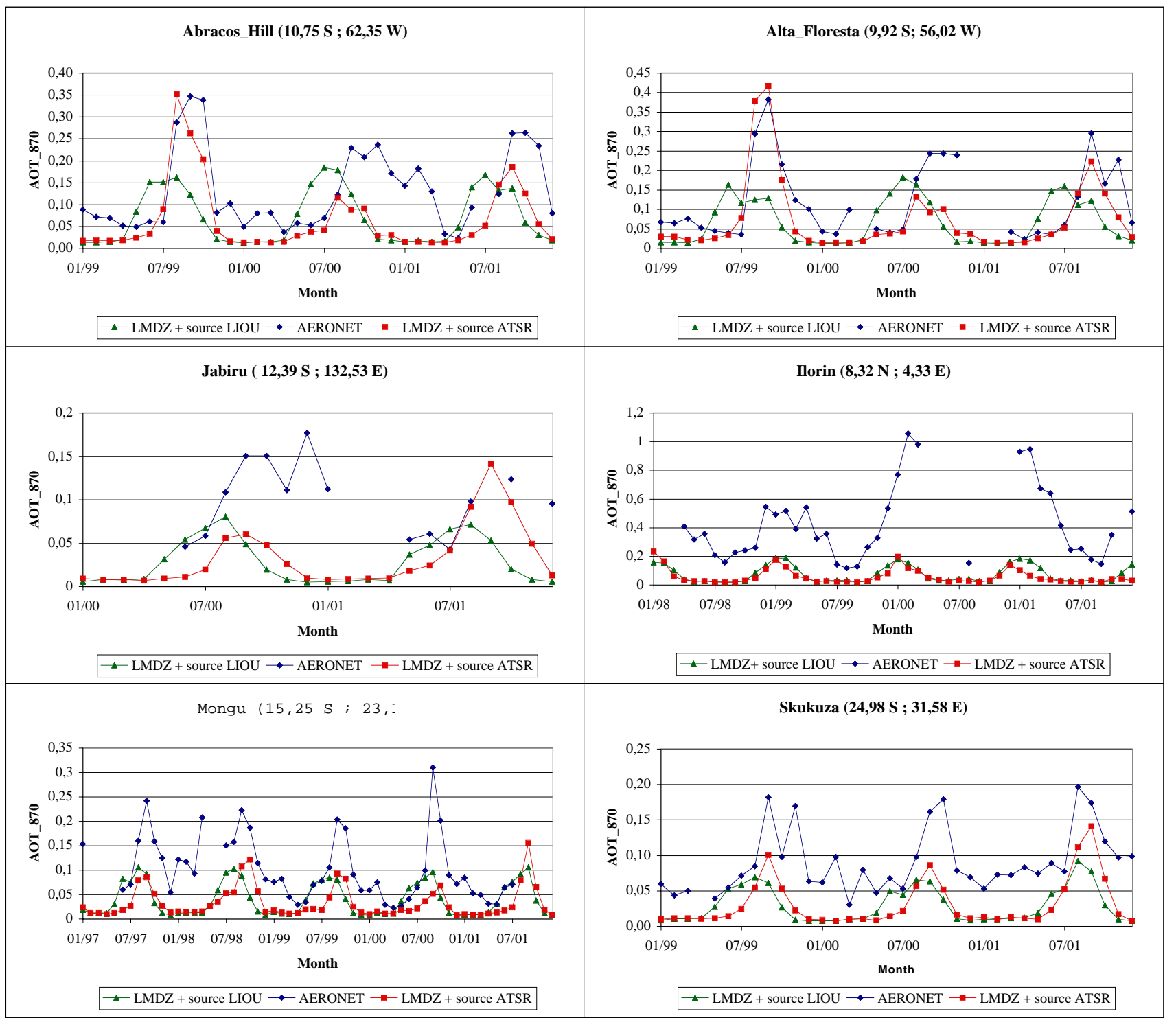

Fig. 4. Aerosol optical thickness measured by AERONET sunphotometer (blue curve) compared to LMDZ estimates with the new sources (red curve) and with the previous sources (green curve).

GLOBSCAR in the northern region). A few regions show significant differences between the proxies however, with the burnt area product showing an earlier season than the hotspot based products. This feature is strongly apparent over South Africa. Note that, the optical depths - another proxy of biomass burning activity - measured by the AERONET stations Mongu $\left(15^{\circ} \mathrm{S}, 23^{\circ} \mathrm{E}\right)$ and Skukuza $\left(24^{\circ} \mathrm{S}, 31^{\circ} \mathrm{E}\right)$ are maximum in September and October 2000 (see Fig. 4), thus more in agreement with the hot-spot products than with the burnt area products. Indonesia is another region with strong differences between the proxies. Indeed, both burnt area product show a well-marked seasonal cycle, whereas the hot-spot products detect fire over most of the year. The three products based on the hot-spot show rather similar profiles, with correlated month-to-month variability, so that the differences cannot be attributed to the night time only detection of the ATSR.

These analyse demonstrate that in most cases, the nighttime only ATSR product show a seasonal cycle that is consistent with the other proxies. In several cases, the burnt area products reach their maximum earlier than the fire count products. The differences between the burnt area products and those based on the hot-spots are not larger when using a night-only proxy (ATSR) than when using a night+day one (AVHRR or TRMM). This indicates that, although all products do have uncertainties, the night time restriction does not appear to be significant. 

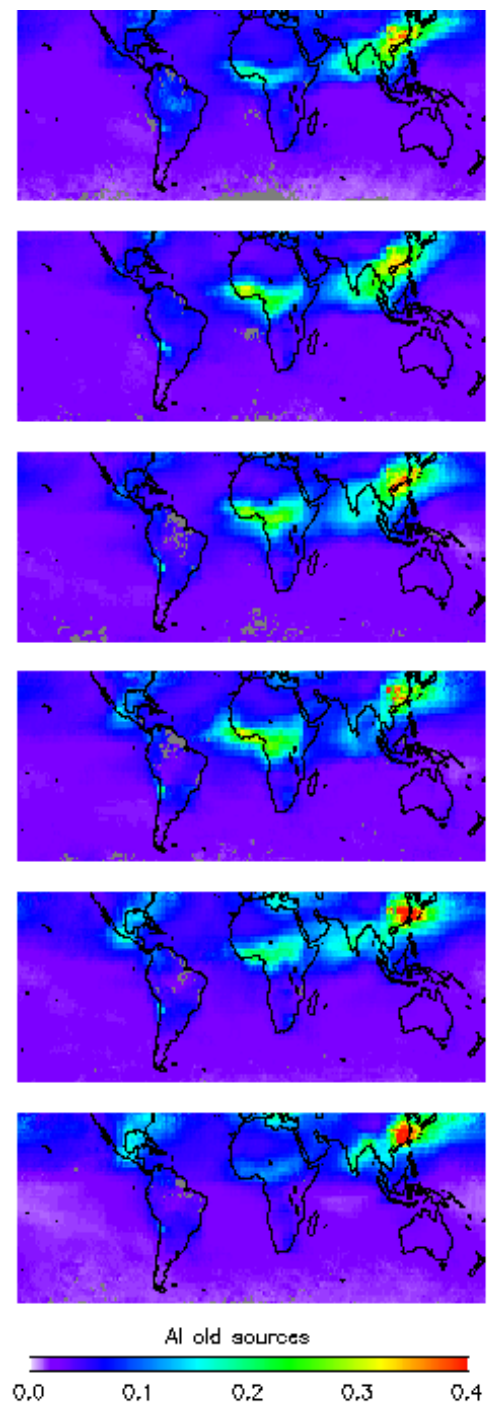
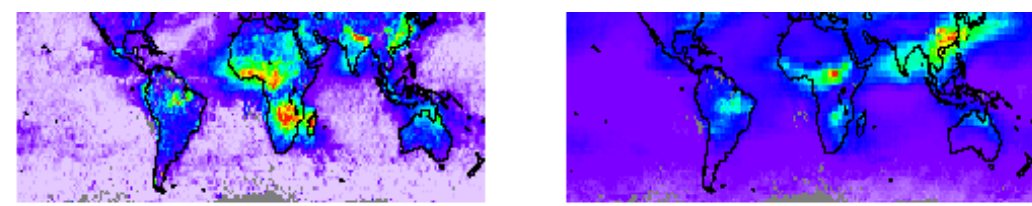

nov96
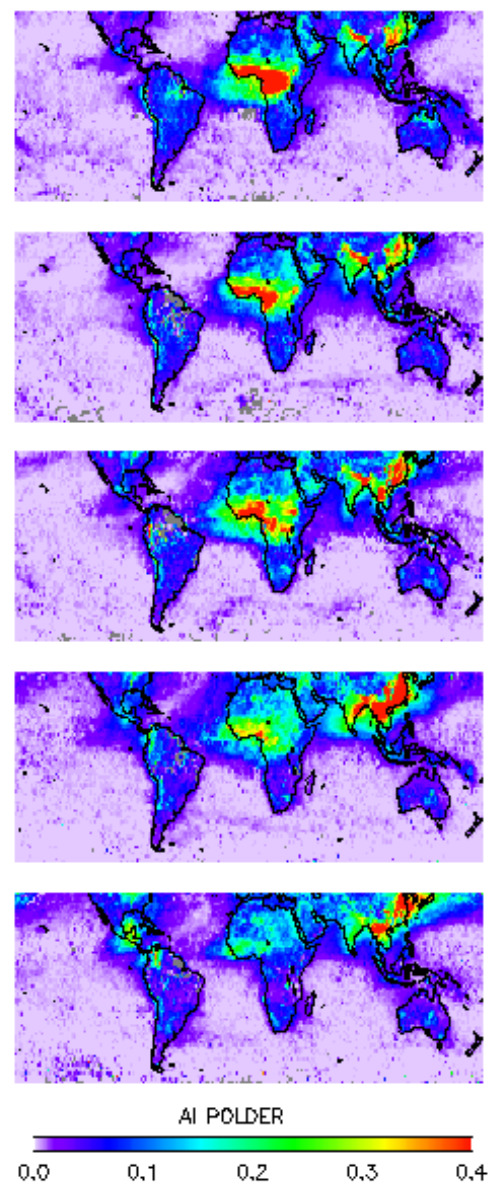

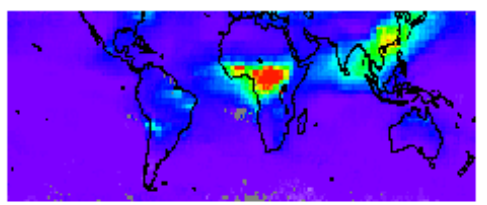

$\operatorname{dec} 6$

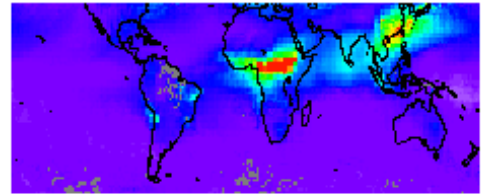

jan97

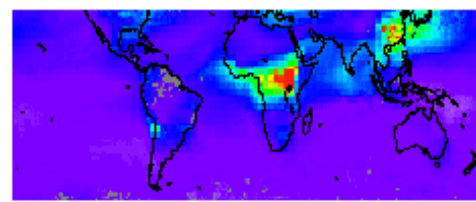

feb97

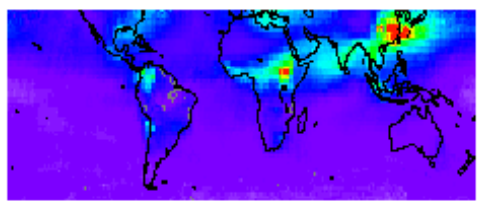

$\operatorname{mar} 97$

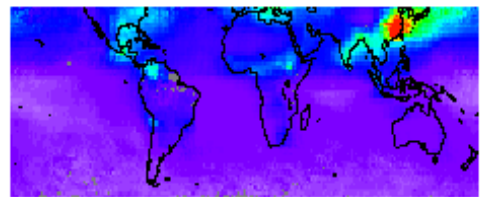

apra7

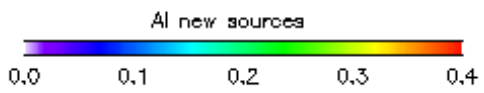

Fig. 5a. Comparisons between POLDER AI and LMDZ AI using both the original and the new sources from November 1996 to April 1997. LMDZ AI is obtained from AOT865 assuming an Angström coefficient equal to 1.5 (Dubovik et al., 2002; Liousse et al., 1995). Note that all the monthly means are computed for the days when POLDER data are available.

\subsection{Other causes of uncertainty}

Cloud coverage is also a source of uncertainty as it prevents the detection of surface fires. We have attempted to correct for the cloud coverage using a monthly climatology. Nevertheless significant uncertainty remains as the cloud cover may differ from the climatology (in particular during specific meteorological events) and also because the night-time mean cloud cover may differ from the daily climatology that we use.

Another potential problem results from the satellite coverage that increases with latitude (a high latitude point is sampled more frequently than a low latitude one), augmenting the probability of fire detection. On the other hand, the boxes of Fig. 1 are small enough so that the satellite revisit frequency does not change significantly within a box. As our method computes EC box by box, the variation of satellite coverage with the latitude is implicitly accounted for.

Moreover, the geo-location precision of the ATSR has been significantly affected during the year 2001 with a misregistration of up to $40 \mathrm{~km}$. This distance is small in comparison with the sizes of our boxes and typical size of areas affected by biomass burning. As a consequence, misregistration shall have a small impact to our results, except for areas affected by industrial flares as our detection and removal procedure is based on a persistent signal within a $3 \mathrm{~km}$ radius.

Finally, these maps have been made assuming that in each box, the emission efficiency of fires for BC or OC has no seasonal or interannual variation (EC is constant). This is 

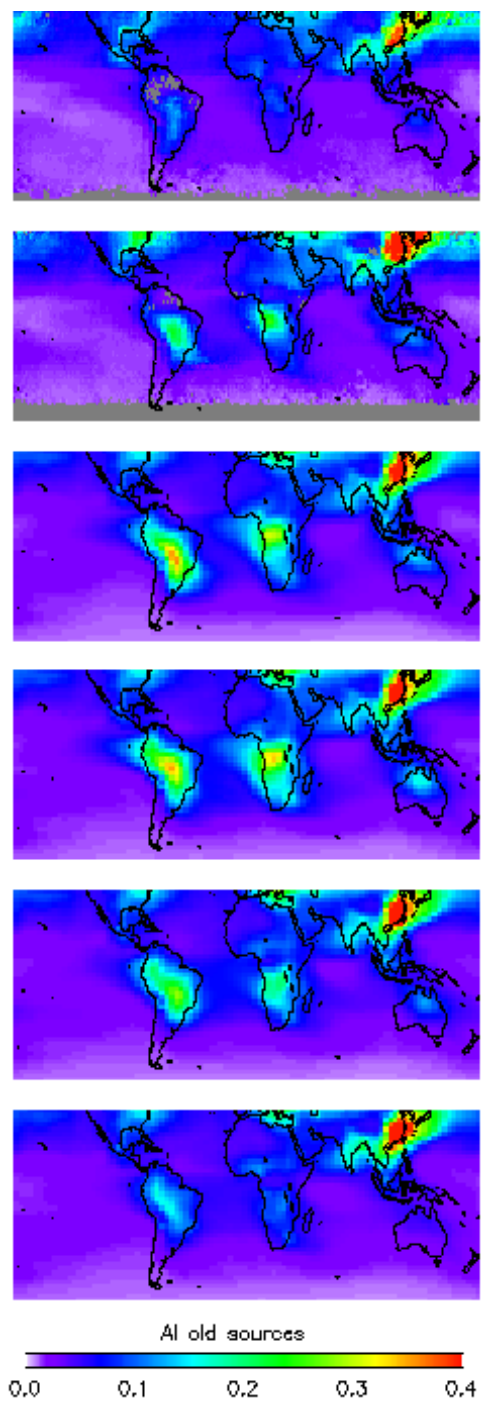
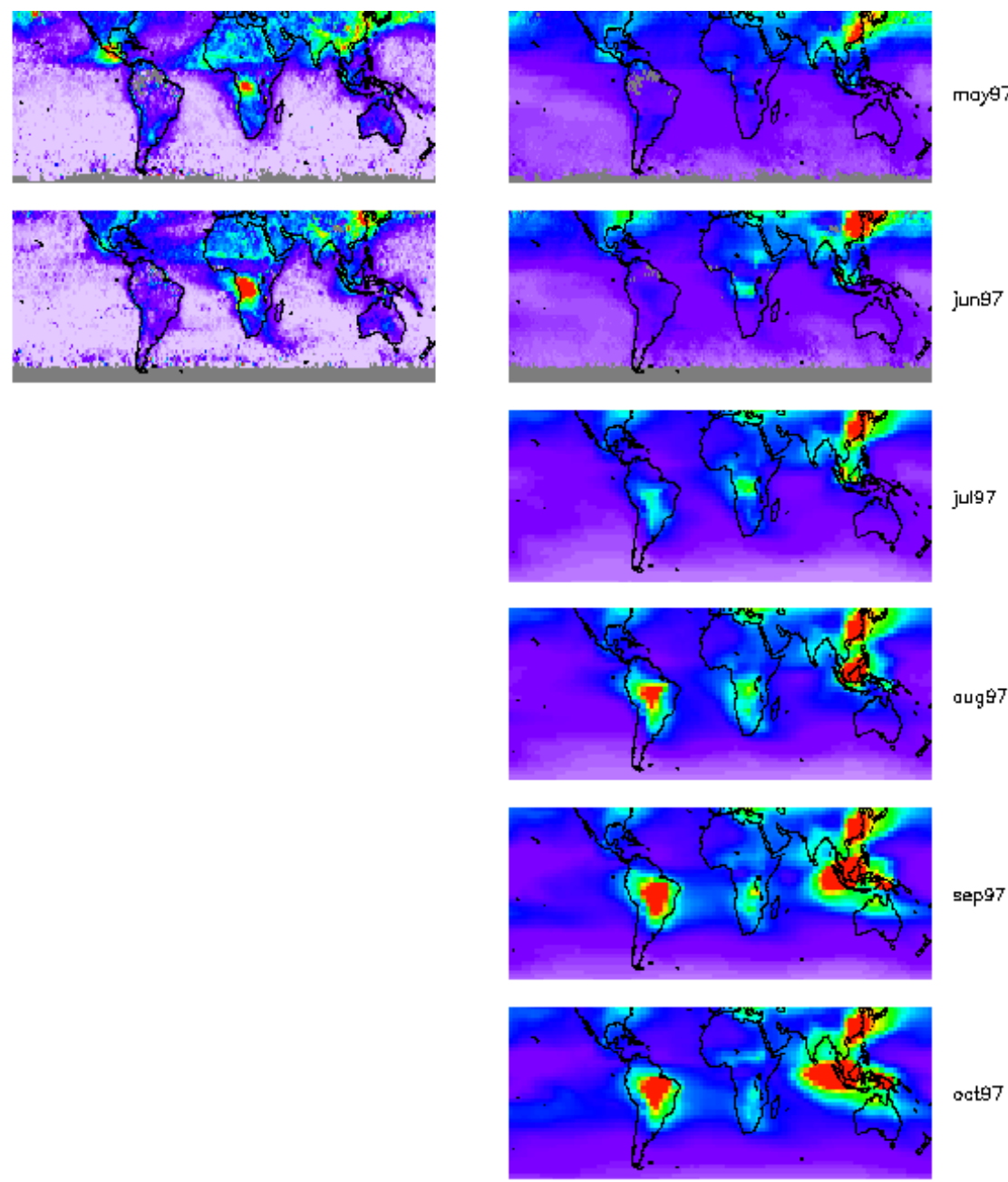

$\operatorname{oct} 97$

Fig. 5b. Comparisons between POLDER AI and LMDZ AI using both the original and the new sources from May 1997 to October 1997. LMDZ AI is obtained from AOT865 assuming an Angström coefficient equal to 1.5 (Dubovik et al., 2002; Liousse et al., 1995). Note that all the monthly means are computed for the days when POLDER data are available.

a rather strong assumption as, for a given vegetation type, the emitted quantities depend on several parameters such as ground humidity, vegetation state or burns history, that vary with the season.

\section{Results and validation}

Both original and satellite-corrected emission maps have been used as input of the Laboratoire de Météorologie Dynamique (LMD) General Circulation Model, LMDz, coupled with INCA (Interaction with Chemistry and Aerosols) which is an emission/chemistry model (http://www.ipsl.jussieu.fr/ $\sim$ dhaer/inca/). We use the model with a resolution of $96 \times 72$ $(3.75 \times 2.5$ degrees in longitude and latitude) and 19 hybrid vertical levels. Only carbonaceous aerosols were analyzed in this study. The model can include its own dynamics, although we nudged here the meteorological fields from the 6hourly ECMWF reanalysis. It generates fields of aerosol load $\left[\mathrm{g} . \mathrm{m}^{-2}\right.$ ] that are converted into optical thicknesses at $865 \mathrm{~nm}$ using constant factors $\left(3.5 \mathrm{~m}^{2} . \mathrm{g}^{-1}\right.$ for OC and $4.5 \mathrm{~m}^{2} . \mathrm{g}^{-1}$ for BC, (Dubovik et al., 2002; Liousse et al., 1995, 1996) based on typical size distributions of biomass burning aerosols.

\subsection{Seasonal cycle}

Ground-based measurements from AERONET (Holben et al., 1998) stations in South America, Africa and Australia are used to validate our simulations. Chin et al. (2002) evaluates the simulations of the GOCART aerosol transport model, using biomass burning emissions from Duncan et al. (2003), 
for the different aerosol components through a comparison to AERONET data. More than 20 AERONET sites are used for the comparison, although only five of them are significantly affected by biomass burning emissions. Here, we show several seasonal cycles whereas Chin et al. (2002) only analyze a mean cycle. These year-to-year comparisons are essential as there is significant interannual variability, which results both from the emissions and the meteorology. Comparisons are also made with satellite observations from the POLDER (POLarization and Directionality of the Earth Reflectances, Deschamps et al., 1994) spaceborne instrument, which is well suited to study aerosols and in particular biomass burning aerosols. The Aerosol Index (AI) from POLDER (Deuzé et al., 2001), available both over land and ocean, is an indicator of submicronic aerosol load only, thus mainly sulfate, $\mathrm{BC}$ and OC. The analysis of POLDER retrievals (Tanré et al., 2001) provides a rough identification of the aerosol origin.

Figure 4 shows the mean AERONET Aerosol Optical Thickness at $870 \mathrm{~nm}$ (AOT870) (in blue), the simulation results using the new sources (red) and those using the previous sources from Liousse et al. (1996) (in green) at six different AERONET sites. Two type of information are shown in Fig. 4. First, the information on the phase of the burning season. The improvements to the seasonal cycle are given by the phasing of the simulated curves (red and green) with the observation curve (blue). The other information concerns the aerosol load, which is directly linked to the amplitude of the curves. The method presented here only impacts the spatial and temporal distribution of fires but not the mean emitted quantities as we assume the total annual estimates of the original inventory to be correct averaged estimates.

In a first step, we discuss the results over South America, where Alta Floresta $\left(9^{\circ} \mathrm{S}, 56^{\circ} \mathrm{W}\right)$ and Abracos Hill $\left(10^{\circ} \mathrm{S}\right.$, $62^{\circ} \mathrm{W}$ ) are selected because long-time series of data are available. AERONET data show the impact of the biomass burning activity from August to November with a maximum value generally in September during three consecutive years from 1999 to 2001. The correction of the emission inventories using the satellite data shift the period with a large aerosol load by typically two months. Although there are some disagreement in terms of optical thickness between the simulations and the sunphotometer measurements, in particular during the later part of the burning season, the cycle is clearly improved. The observed aerosol load cycle for the year 2000 is clearly different than for the other years. It is not reproduced by the simulation. On the other hand, none of the biomass burning proxies (see Fig. 3) shows a significant burning activity during the later part of the year, while a large aerosol load is observed. Therefore, none method based on these satellite products would reproduce this specific event.

Over Australia, Jabiru $\left(12^{\circ} \mathrm{S}, 132^{\circ} \mathrm{E}\right)$ is the only site in the North with sufficient amount of data. Although the seasonal cycle is not complete, the maximum aerosol load appears to be in September and October. In addition, the comparisons of the diverse global fire products (see Fig. 3) show that the burning season starts in May/June and ends in November with the maximum of detected fire from August to October. Note that only GLOBSCAR show relatively large amount of fire earlier (in June and July) in disagreement with GBA2000 and all fire count products. Hence, methods based on the other fire products (except GLOBSCAR) would have reproduced a similar seasonal cycle. The corrected emission maps lead to a better agreement of the seasonal cycle with the different biomass burning proxies over North Australia although the magnitude of the optical depth is somewhat too small.

Over the African continent there are two main areas of biomass burning. One extends along $10^{\circ}$ of latitude with the main activity between November and February. The other large burning area of Africa extends over the southern subtropics, with an activity that starts in June in the western part of the area, moves to the East and Madagascar, and ends in November. Figure 4 shows the comparison results over Ilorin $\left(8^{\circ} \mathrm{N}, 4^{\circ} \mathrm{E}\right)$, Mongu $\left(15^{\circ} \mathrm{S}, 23^{\circ} \mathrm{E}\right)$ and Skukuza $\left(24^{\circ} \mathrm{S}, 31^{\circ} \mathrm{E}\right)$ sites, which were chosen for their extended time series. These comparisons indicate that the original emission maps show a satisfactory seasonal cycle that is not improved nor degraded using the information from the ATSR. On the other hand, the modeled optical thicknesses are much smaller than the observations, which can be a result of an underestimate of the emission fluxes, although the factor used to convert masses to optical thicknesses can also be blamed. Chin et al. (2002) show that Ilorin is also influenced by dust aerosols, which are not included in the simulations.

In order to have a global view of the representation of carbonaceous aerosols in the model, we show on Figs. 5a and $\mathrm{b}$ a comparison between POLDER AI (a good index for carbonaceous and sulfate aerosols) and LMDZ AI. The simulation overlaps the period of the POLDER data, i.e. from November 1996 to October 1997. For consistency with the satellite measurements, the model simulates the source and cycle of carbonaceous and sulfate (Boucher et al., 2002) aerosols. The global picture confirms several findings of the AERONET comparisons. Figure 5a shows that both inventories depict correctly the phase of the aerosol load seasonal cycle in Western Africa, although the maximum of the aerosol index is shifted to the East in February in the simulation (new sources). In South Africa, the model seems to under predict the aerosol index in June (Fig. 5b). The satellite data confirm that there is no significant aerosol load over South America from May to June (see middle panel on Fig. 5b). The model predictions using the ATSR-derived inventory are in agreement with observations, contrary to what the model predicts with the original sources in May and June. The use of information from ATSR fires brings about an even larger change in the phasing of biomass burning over North Australia. The original sources yield a significant aerosol load from May to September, when the corrected sources indicate that the fire activity starts in September. 


\section{September 1997}
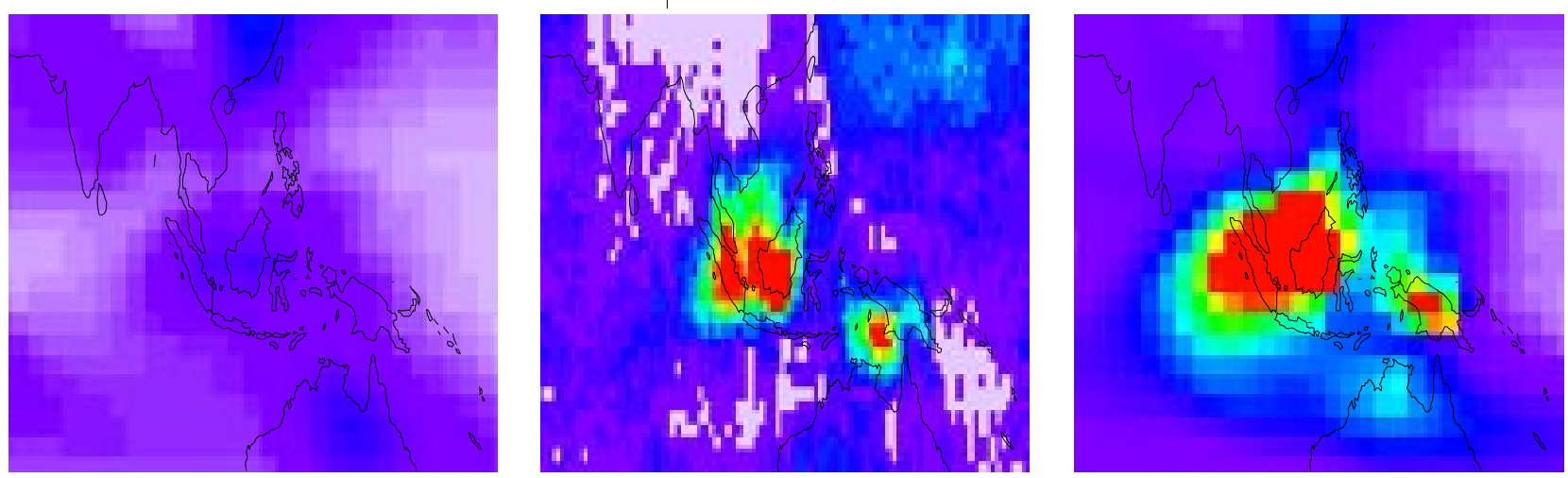

October 1997
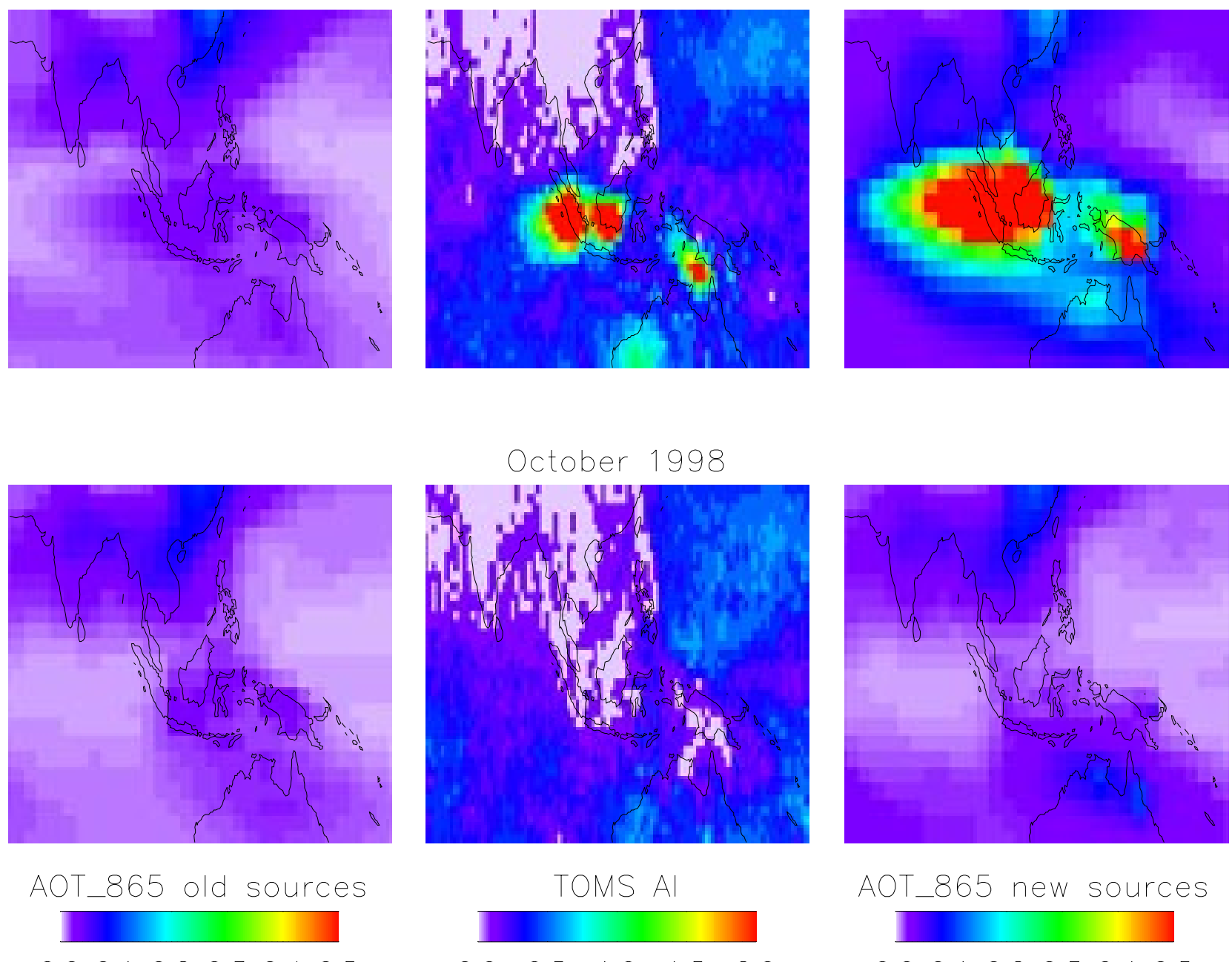

$\begin{array}{llllll}0.0 & 0.1 & 0.2 & 0.3 & 0.4 & 0.5\end{array}$
October 1998
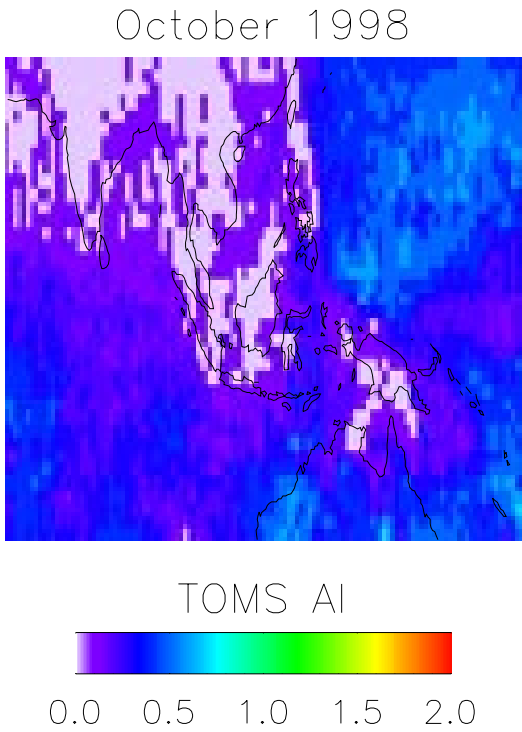
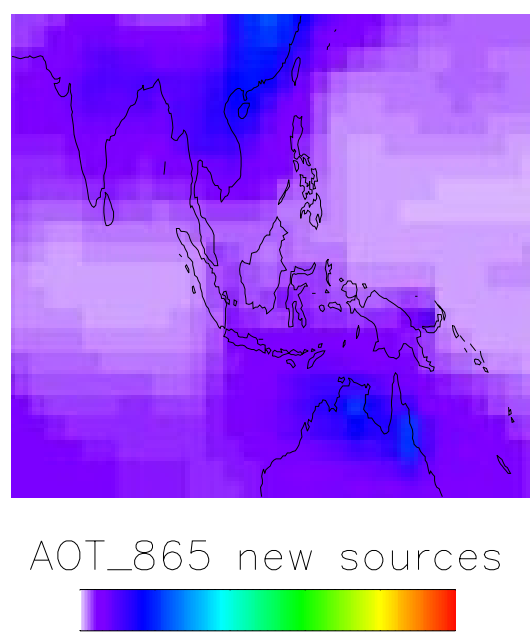

$\begin{array}{llllll}0.0 & 0.1 & 0.2 & 0.3 & 0.4 & 0.5\end{array}$

Fig. 6. Comparison of the aerosol index from the Earth-Probe TOMS (middle panels) with simulated aerosol optical depths at $865 \mathrm{~nm}$ simulated with Liousse et al. (1996) inventory (left panels) and newly derived sources from ATSR fire counts (right panels). Color scales were chosen from 0 to 2 for TOMS AI and from 0 to 0.5 for LMDZ AOT in order to be consistent with the assumed value of 5 for the slope of the fit between the TOMS AI and the AOT at $865 \mathrm{~nm}$ based upon the Chiapello et al. (2000) study. 
Table 1. Quantities of carbonaceous aerosols emitted by biomass burning (including savanna, forest and agricultural fires) in the ATSRderived inventory. BC emissions are in $\mathrm{Tg}$ of Carbon $(\mathrm{TgC})$ per year and $\mathrm{OC}$ emissions are in $\mathrm{Tg}$ of mass ( $\mathrm{Tg}$ ) per year. BC and $\mathrm{OC}$ (blue) correspond to the emissions of the blue boxes of Fig. 1 (boreal latitudes) and BC and OC (red) to the emissions of the red boxes

\begin{tabular}{ccccccc}
\hline & BC (blue) & BC (red) & TOTAL BC & OC (blue) & OC (red) & TOTAL OC \\
\hline 1997 & 0.10 & 7.00 & 7,10 & 1.37 & 59.41 & 60,78 \\
1998 & 0.41 & 6.09 & 6,50 & 7.55 & 51.64 & 59,19 \\
1999 & 0.15 & 3.79 & 3,94 & 2.47 & 31.26 & 33,73 \\
2000 & 0.16 & 3.20 & 3,36 & 2.70 & 26.45 & 29,15 \\
2001 & 0.11 & 3.09 & 3,20 & 1.97 & 25.48 & 27,45 \\
\hline
\end{tabular}

\subsection{Interannual variability}

Table 1 summarizes the emitted quantities of carbonaceous aerosols in the new ATSR-derived inventory for each year of ATSR observations. We have assumed that the total annual estimates of the original inventories (Liousse et al., 1996 and Lavoué et al., 2000) - as climatological averaged values - are correct. In the original Liousse et al. (1996) inventory, emissions represent $35.2 \mathrm{Tg}$ of $\mathrm{OC}$ and $4.63 \mathrm{Tg}$ of $\mathrm{BC}$ (including savanna, tropical forests and agricultural fires; excluding domestic fuels). Year 1999 compares well with these estimates whereas years 1997 and 1998 are a factor 1.5-1.7 larger than the averaged values. This increase in the emissions is mostly due to the Indonesian fires event of September/October 1997. On the other hand, emissions of 2000 and 2001 are smaller (factor of 0.65 to 0.75 ) than those of the climatological year.

In order to show that the proposed method accounts for large interannual variations, we now focus on the particular event of Indonesian fires that took place in September/October 1997 (Nakajima et al., 1999), thought to be a consequence of 1997/1998 El Niño. This phenomenon was well captured by the Earth-Probe TOMS (Herman et al., 1997). Figure 6 shows a comparison between TOMS AI and LMDZ AOT865 based upon the Liousse et al. (1996) inventory and upon the ATSR-derived inventory. Note that although an exact quantitative comparison is difficult, the emissions from these fires are reproduced qualitatively through the use of ATSR fire counts. TOMS measurements indicate a large aerosol load over Indonesia in September and October 1997. The consequence of the abnormal fire activity is not depicted with the original inventory, as one would expect for a climatological source. By contrast, the use of ATSR-based emission maps leads to an aerosol index significantly larger than for other years (i.e. October 1998 in Fig. 6). We note also that the spatial distribution of the aerosol loads compares well with the TOMS observations. In addition, Nakajima et al. (1999) have estimated from the AVHRR data that the region of optical thickness at $500 \mathrm{~nm}$ larger than 0.5 reaches the Indian and Australian coasts and covers an area such as $2000 \times 5000 \mathrm{~km}^{2}$. Such high optical depths have been observed from September to November 1997. Hence, the spatial distribution of the fire event reproduced by the simulation seems correct although the optical depths appear overestimated. This comes from an overestimation of the emissions due to a high EC computed for the Indonesian region. A possible explanation is that too low fires are detected during "normal years", which might be due to high cloud cover ( $65 \%$ to $85 \%$ ) over Indonesia.

\section{Conclusions}

The method described in this paper provides a simple way to introduce biomass burning seasonal cycles into already existing inventories and to take into account interannual variations. The comparison of the aerosol transport simulations to in-situ and satellite measurements clearly shows an improvement when using the fire count information. In particular, the aerosol load seasonal cycle over South America and Australia, which are not well represented in the original inventories, are now better depicted. The comparison with POLDER products provides a global and qualitative validation of the seasonal cycle of biomass burning aerosol. Due to the rather short observing period of POLDER-1, the analysis of the seasonal cycle is incomplete, and we are expecting additional information from the recently launched POLDER-2 instrument onboard ADEOS-II. The comparison of the model simulations with AERONET data allows more quantitative comparison over specific sites. These comparisons confirm the improvement when using the fire count data to constrain the seasonal cycle and the inter-annual events, although significant discrepancies were found in the amplitude of the aerosol load in particular toward the end of the biomass burning season.

The present study focuses on the use of ATSR data because a five years period was available at the time of our analysis. A comparison of this biomass burning proxy to others, limited to the year 2000, indicate a general good agreement. The derivation of aerosol emission from burnt surfaces requires less assumption than from hot-spot counts. Global inventories of aerosol emission from such datasets as GLOBSCAR (Hoelzemann et al., 2003) will be of particular interest when multi-year estimates become available. 
Acknowledgements. The emission factors are based on the ATSR World Fire Atlas managed by the European Space Agency (ESA). We thank Cathy Liousse for providing the $\mathrm{OC}$ and $\mathrm{BC}$ emission inventories. We thank the principal investigators Brent Holben, Paulo Artaxo, Ross Mitchell and Rachel Pinker and the AERONET program team for providing the ground-based aerosol data used in this work. The satellite data come from the POLDER instrument developed by the Centre National d'Etudes Spatiales onboard the ADEOS platform developed by NASDA.

\section{References}

Arino, O. and Melinotte, J. M.: Fire index atlas, Earth observation quaterly, 50, 1995.

Boucher, O., Pham, M., and Venkataraman, C.: Simulation of the atmospheric sulfur cycle in the Laboratoire de Météorologie Dynamique General Circulation Model. Model description, model evaluation, and global and European budgets, Note scientifique de l'IPSL, 23, 2002 (available at http://www.ipsl.jussieu.fr/poles/ Modelisation/NotesSciences.htm).

Bréon, F.-M., Tanré, D., and Generoso, S.: Aerosol effect on cloud droplet size monitored from satellite, Science, 295, 834-838, 2002.

Charlson, R. J., Schwartz, S. E., Hales, J. M., Cess, R. D., Coakley, J. A. J., Hansen, J. E., and Hofmann, D. J.: Climate forcing by anthropogenic aerosols, Science, 255, 423-430, 1992.

Chiapello, I., Goloub, P., Tanré, D., Marchand, A., Herman, J., and Torres, O.: Aerosol detection by TOMS and POLDER over oceanic regions, Journal of Geophysical Research - Atmospheres, 105, 7133-7142, 2000.

Chin, M., Ginoux, P., Kinne, S., Torres, O., Holben, B. N., Duncan, B. N., and Martin, R. V., Logan, J. A., Higurashi, A., and Nakajima, T.: Tropospheric aerosols optical thickness from the GOCART model and comparisons with satellite and sun photometer measurements, Journal of the Atmospheric Sciences, 59, 461-483, 2002.

Cooke, W. F., Koffi, B., and Grégoire, J.-M.: Seasonality of vegetation fires in Africa from remote sensing data and application to a global chemistry model, Journal of Geophysical Research, 101, 21 051-21 065, 1996.

Deschamps, P.-Y., Bréon, F.-M., Leroy, M., Podaire, A., Bricaud, A., Buriez, J.-C., and Sèze, G.: The POLDER mission: instrument characteristics and scientific objectives, IEEE Transactions on geoscience and remote sensing, 32, 598-615, 1994.

Deuzé, J. L., Bréon, F.-M., Devaux, C., Goloub, P., Herman, M., Lafrance, B., Maignan, F., Marchand, A., Nadal, F., Perry, G., and Tanré, D.: Remote sensing of aerosols over land surfaces from POLDER-ADEOS-1 polarized measurements, Journal of Geophysical Research, 106, 4913-4926, 2001.

Dubovik, O., Holben, B., Eck, T. F., Smirnov, A., Kaufman, Y. J., King, M. D., Tanré, D., and Slutsker, I.: Variability of absorption and optical properties of key aerosol types observed in worldwide locations, Journal of the Atmospheric Sciences, 59, 590-608, 2002.

Duncan, B. N., Randall, V. M., Staudt, A. C., Yevich, R., and logan, J. A.: Interannual and seasonal variability of biomass burning emissions constrained by satellite observations, Journal of Geophysical Research, 108, 4040, doi:10.129/2002JD002378, 2003.
Giglio, L., Kendall, J. D., and Mack, R.: A multi-year active fire data set for the tropics derived from the TRMM VIRS, International Journal of Remote Sensing, in press, 2003.

Giglio, L., Kendall, J. D., and Tucker, C. J.: Remote sensing of fires with the TRMM VIRS, International Journal of Remote Sensing, 21, 203-207, 2000.

Grégoire, J.-M., Tansey, K., and Silva, J. M. N.: The GBA2000 initiative: Developing a global burned area database from SPOTVEGETATION imagery, International Journal of Remote Sensing, 24, 1369-1376, 2003.

Haywood, J. and Boucher, O.: Estimates of the direct and indirect radiative forcing due to tropospheric aerosols: a review, Reviews of Geophysics, 38, 513-543, 2000.

Herman, J. R., Bhartia, P. K., Torres, O., Hsu, C., Seftor, C., and Celarier, E.: Global distribution of UV-absorbing aerosols from Nimbus 7/TOMS data, Journal of Geophysical Research, 102, 16911-16922, 1997.

Hoelzemann, J. J., Brasseur, G. P., Granier, C., Schultz, M. G. and Simon, M.: The Global Wildfire Emission Model GWEM: a new approach with global area burnt data, Journal of Geophysical Research, submitted, 2003.

Holben, B. N., Eck, T. F., Slutsker, I., Tanré, D., Buis, J. P., Setzer, A., Vermote, E., Reagan, J. A., Kaufman, Y. J., Nakajima, T., Lavenu, F., Jankowiak, I., and Smirnov, A.: AERONET - A federated intrument network and data archive for aerosol characterization, Remote Sensing of Environment, 66, 1-16, 1998.

IPCC, Climate change 2001: The scientific basis, contribution of working group I to the third assessment. Report of the Intergovernmental Panel on Climate Change, Cambridge university press, New York, USA, 881 pp. 2001.

Lavoué, D., Liousse, C., Cachier, H., Stocks, B. J., and Goldammer, J. G.: Modeling of carbonaceous particles emitted by boreal and temperate wildfires at northern latitudes, Journal of Geophysical Research, 105, 26 871-26 890, 2000.

Léon, J.-F., Chazette, P., Pelon, J., Dulac, F., and Randriamiarisoa, H.: Aerosol direct radiative impact over the INDOEX area based on passive and active remote sensing, Journal of Geophysical Research, 107, 10129, doi:10.1029/2000JD000116, 2002.

Liousse, C., Devaux, C., Dulac, F., and Cachier, H.: Aging of savanna biomass burning aerosols: consequences on their optical properties, Journal of Atmospheric Chemistry, 22, 1-17, 1995.

Liousse, C., Penner, J. E., Chuang, C., Walton, J. J., Eddleman, H., and Cachier, H.: A global three-dimensional model study of carbonaceous aerosols, Journal of Geophysical Research, 101, 19411-19432, 1996.

Nakajima, T., Higurashi, A., Takeuchi, N., and Herman, J. R.: Satellite and ground-based study of optical properties of 1997 Indonesian forest fire aerosols, Geophysical Research Letters, 26, 24212424, 1999.

New, M., Hulme, M., and Jones, P.: Representing twentieth-century space-time climate variability. Part I: Development of a 196190 mean monthly terrestrial climatology, Journal of Climate, 12, 829-856, 1999.

Schultz, M. G.: On the use of ATSR fire count data to estimate the seasonal and interannual variability of vegetation fire emissions, Atmospheric Chemistry and Physics, 2, 387-395, 2002

Simon, M., Plummer, S., Fierens, F., Hoelzemann, J. J., and Arino, O.: Burnt area detection at global scale using ATSR-2: the GLOBSCAR products and their qualification, Journal of Geo- 
physical Research, submitted, 2003.

Tanré, D., Bréon, F.-M., Deuzé, J. L., Herman, M., Goloub, P., Nadal, F., and Marchand, A.: Global observation of anthropogenic aerosols from satellite, Geophysical Research Letters, 28, 4555-4558, 2001.
Twomey, S.: The influence of pollution on the shortwave albedo of clouds, Journal of the Atmospheric Sciences, 34, 1149, 1977. 